\title{
Potential sperm contributions to the murine zygote predicted by in silico analysis
}

\author{
Panagiotis Ntostis ${ }^{1,2}$, Deborah Carter ${ }^{3}$, David Iles ${ }^{1}$, John Huntriss ${ }^{1}$, Maria Tzetis ${ }^{2}$ and \\ David Miller ${ }^{1}$ \\ ${ }^{1}$ Leeds Institute of Cardiovascular and Metabolic Medicine, University of Leeds, Leeds, West Yorkshire, UK, \\ ${ }^{2}$ Department of Medical Genetics, St. Sophia's Children Hospital, School of Medicine, National and Kapodistrian \\ University of Athens, Athens, Attiki, Greece and ${ }^{3}$ Leeds Institute of Molecular Medicine, University of Leeds, Leeds, \\ West Yorkshire, UK \\ Correspondence should be addressed to D Miller; Email: d.miller@leeds.ac.uk
}

\begin{abstract}
Paternal contributions to the zygote are thought to extend beyond delivery of the genome and paternal RNAs have been linked to epigenetic transgenerational inheritance in different species. In addition, sperm-egg fusion activates several downstream processes that contribute to zygote formation, including PLC zeta-mediated egg activation and maternal RNA clearance. Since a third of the preimplantation developmental period in the mouse occurs prior to the first cleavage stage, there is ample time for paternal RNAs or their encoded proteins potentially to interact and participate in early zygotic activities. To investigate this possibility, a bespoke next-generation RNA sequencing pipeline was employed for the first time to characterise and compare transcripts obtained from isolated murine sperm, MII eggs and pre-cleavage stage zygotes. Gene network analysis was then employed to identify potential interactions between paternally and maternally derived factors during the murine egg-to-zygote transition involving RNA clearance, protein clearance and post-transcriptional regulation of gene expression. Our in silico approach looked for factors in sperm, eggs and zygotes that could potentially interact co-operatively and synergistically during zygote formation. At least five sperm RNAs (Hdac11, Fbxo2, Map1/c3a, Pcbp4 and Zfp821) met these requirements for a paternal contribution, which with complementary maternal co-factors suggest a wider potential for extra-genomic paternal involvement in the developing zygote.

Reproduction (2017) 154 777-788
\end{abstract}

\section{Introduction}

Assuming fertilisation is successful, spermatozoal entry into the egg triggers a series of events that ends with the transformation of the terminally differentiated egg into the totipotent zygote. Alongside the paternal genome, the sperm also delivers non-genomic factors including the microtubule organising centre or centriole (excepting rodents), the oocyte-activating factor, PLCzeta (Saunders et al. 2002, Barroso et al. 2009) and a complex repertoire of RNAs to the egg (Ostermeier et al. 2004, Yuan et al. 2015). Both sperm and egg are transcriptionally silent (Braun 2000, Richter \& Lasko 2011 ) and the egg-to-zygote transition (EZT) occurs in the absence of transcription (Evsikov et al. 2006). While somatic nuclear cloning (Gurdon \& Melton 2008) and the generation of viable gynogenetic mice (Kono et al. 2004) suggest that maternal factors alone are sufficient to guide early embryo development, these processes are grossly inefficient and structural or signaling factors from the sperm may complement maternal factors that could participate in and aid the early programming of embryonic development (Jodar et al. 2015, Miller 2015).

RNAs can epigenetically affect transgenerational inheritance through specific small non-coding RNAs (sncRNAs) and associated RNA-binding proteins (Rodgers et al. 2015, Chen et al. 2016). In Caenorhabditis elegans, a hybrid strain crossing showed that approximately $10 \%$ of embryonic RNA is of paternal origin with functional importance during EZT and possibly embryogenesis (Stoeckius et al. 2014b). An equivalent paternal contribution to the mammalian zygote will be small by comparison, but evidence of the potential for sperm RNAs (or their translated proteins) to contribute to and participate in zygote formation is strong and worthy of further investigation.

Early molecular processes in the zygote can be classified into three main categories including maternal clearance, chromatin remodeling and eventually zygotic genome activation (ZGA) (Lee et al. 2013). Maternal clearance is the process of removing maternal factors including RNAs and proteins essential for oogenesis that become surplus to requirements after fertilisation 
(Tadros \& Lipshitz 2009). Post-transcriptional regulation plays a role during EZT and includes the destruction of maternal mRNAs guided by their 3' untranslated (3' UTR) sequences (Giraldez 2010). Compared with approximately 2000 proteins reported in pre cleavage stage zygotes of $M$. musculus, over 3500 proteins have been identified in metaphase II eggs (Wang et al. 2010, Yurttas et al. 2010). During the embryonic development, this removal of maternal factors is guided mainly by ubiquitin-dependent degradation pathways and by autophagy (Marlow 2010).

While transcriptionally inert, MII eggs and zygotes are likely to be translationally active (Potireddy et al. 2006, Fang et al. 2014), leaving open the possibility for sperm RNAs to be translated into proteins following their introduction to the egg (Fang et al. 2014). We reasoned that a potential non-genomic paternal contribution would most likely involve interactions with maternal factors responsible for the regulation of gene expression prior to the EZT and the clearance of maternal factors prior to embryonic genome activation. The main objective of the study, therefore, was to see if in silico analysis of RNA sequencing data obtained from sperm, MII eggs and pre cleavage stage zygotes (PCZ but henceforth referred to as zygotes) using an identical bespoke protocol, could highlight potential interactions between paternal and maternal cofactors brought together by fertilisation. Herein, we focus on five, full-length mRNAs present at high levels in murine sperm that with associated maternal cofactors, fit the requirements for a potential paternal, non-genomic metabolic contribution to the zygote.

\section{Materials and methods}

\section{Study design}

RNAs isolated from pooled murine spermatozoa, single MII eggs and single zygotes were sequenced and compared. To help identify paternal RNAs with the potential to participate in EZT events, we looked firstly for candidate RNAs that were highly represented in sperm, thus increasing the probability of being delivered to and translated by the zygote or being translated into protein during the late stages of spermatogenesis and delivered to the MII egg at fertilisation. Secondly, considering the highly fragmented nature of sperm RNA, no less than $80 \%$ of the exonic regions of at least one gene isoform of a 'candidate' paternal cofactor had to be covered by RNA-seq reads, giving a greater potential for the RNA to be functional. Thirdly, sperm RNAs with good sequence coverage were only considered further if their ontological descriptions suggested functions other than spermatogenesis.

A bespoke identical library preparation method and sequencing pipeline were applied to all samples allowing accurate comparative assessment of RNAs across the different samples. The library kit used (Ovation single cell RNASequencing system, NuGEN, CA, USA) has a mix of oligo-dT and random primers targeting a wider range of transcripts, including those with varying poly(A) tail lengths, typically encountered in gamete and zygotic mRNAs (Paranjpe et al. 2013). Cytoscape's GeneMANIA module (see below) was then employed for the in silico analysis investigating potential interactions between gene products of paternal and maternal origin (Warde-Farley et al. 2010).

\section{Ethics}

Experiments involving the use of animals were regulated under the Home Office, UK Animals Scientific Procedures Act (ASPA) under license service PPL 40/3391 approved by the University of Leeds AWERC (Animal Welfare Ethical Review Committee). All animals were culled using cervical dislocation in accordance to Schedule 1 of the ASPA.

\section{Mouse gamete and zygote harvest}

Groups of $\mathrm{C} 57 \mathrm{BL} / 6 \mathrm{~J}$ females were super-ovulated with a $5 \mathrm{IU}$ dose of pregnant mares' serum gonadotropin (PMSG) (Sigma Aldrich) injected intraperitoneally (I/P) on day 1 , followed at day 3 by a $5 \mathrm{IU}$ dose of human chorionic gonadotropin (HCG) (Sigma Aldrich) I/P and mated with vasectomised males to provide MII eggs. The zygote groups were mated to proven C57BL/6] stud males immediately after hCG dosing and checked the following day for post coital plugs. Plugged females were pooled and used for zygote harvest. Both zygote and MII egg groups were sacrificed on day 4 . Oviducts from the zygote and egg groups were harvested separately and suspended in M2 media (Sigma Aldrich). Dissected oviducts were placed into a pre-heated dish of synthetic Human Tubal Fluid (HTF) media (Irvine Scientific, CA, USA) with bovine serum albumin (BSA) (Sigma Aldrich). Cumulus masses were released into the HTF/BSA medium and transferred into a drop of hyaluronidase (Sigma Aldrich) following which, a wide bore pipette was used to strip the eggs and zygotes of their cumulus cells. These were in turn collected by mouth pipette and washed through sequential drops of M2 media (Sigma Aldrich).

\section{Sperm harvest}

The epididymides of fertile C57BL/6 males were dissected out and transferred into pre-warmed HTF (Irvine Scientific). Using a sterile 26G needle, small incisions were made in the cauda and sperm were allowed to swim out before collection by gentle aspiration. Spermatozoa were washed in HTF (Irvine), filtered through an 80-micron mesh (Sigma Aldrich) and centrifuged at $500 \mathrm{~g}$ prior to resuspension and centrifugation through a two-layer $(65-50 \%)$ discontinuous percoll gradient (GE Healthcare Biosciences) at 300g, employing the Prolnsert technology (Nidacon International AB, Gothenburg, Sweden) to facilitate the selective isolation of pelleted spermatozoa while preventing possible contamination by somatic cells (Fourie et al. 2012). Spermatozoa were pelleted at $500 \mathrm{~g}$ and washed twice in Dulbecco's phosphate-buffered saline (DPBS) (Thermo Scientific). Approximately 1 million spermatozoa were harvested before the second wash and Giemsa stained (Sigma Aldrich) to visually confirm lack of other cell types using a Leica Leitz DMRB microscope (Mazurek Optical Services, Southam, UK). 
A

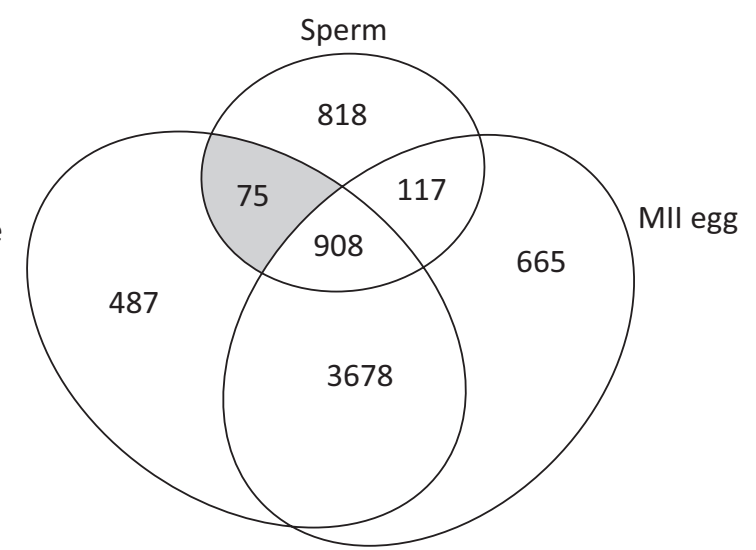

B

Sperm

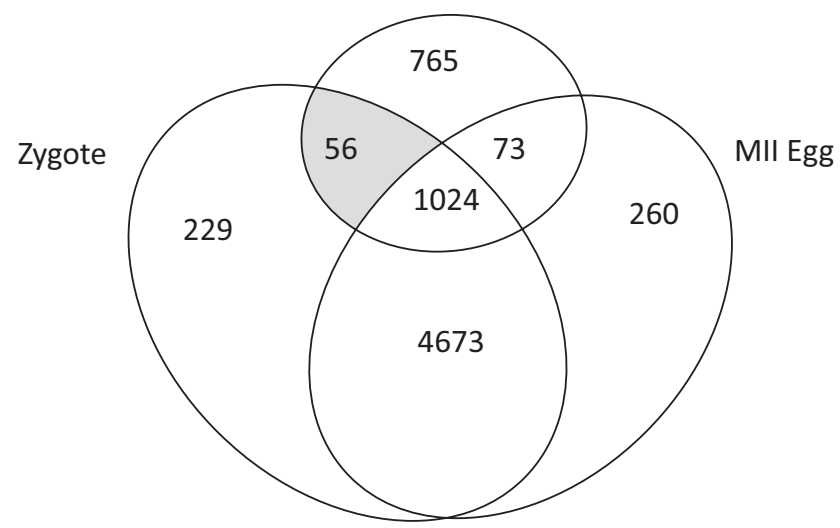

Figure 1 Venn diagrams for the cross-representation of sperm, MII egg and zygote RNAs. Panel A shows the overlaps between all RNAs, aggregated from all biological replicates at $\geq 10$ CPM from each of the three sources. Panel B shows similar overlaps, except that the selected lists for MII eggs and zygotes were obtained after testing with Edge R, which normalises the data and identifies differentially expressed RNAs that are significantly 'up' in MIl eggs or in zygotes. These over-represented RNAs are then added to the list of RNAs common to both MII eggs and zygotes. Complete RNA lists are provided in the Supplementary data.

\section{RNA isolation and library construction}

Sperm RNA was extracted using the method described by Goodrich (Goodrich et al. 2013) with modifications. Briefly, $10^{7}$ spermatozoa were placed in RLT buffer (Qiagen) with $1.5 \% \quad \beta$-mercaptoethanol (Sigma Aldrich) and $0.5 \mathrm{~mm}$ nuclease free stainless steel beads. Following homogenisation with a DisruptorGenie cell disruptor (Thermofisher Scientific), an equal volume of chloroform was added followed by centrifugation at $12,000 \mathrm{~g}\left(4^{\circ} \mathrm{C}\right)$, allowing recovery of the RNA. Prior to library construction, any residual genomic DNA was removed from the samples by digestion with Turbo DNase (Thermofisher Scientific) following the manufacturer's instructions. Quantitative Real-Time PCR (qRT-PCR) using Prm2 and Map1/c3a intron spanning primers with SybrGreen PCR mastermix (Applied Biosystems) was employed to monitor for DNA contamination.

Sperm RNA quality assessment was carried out using the RNA-6000 pico assay (Agilent) on a 2100 Bioanalyzer (Agilent),
Table 1 Top biological processes for source and differentially expressed RNAs.

\begin{tabular}{|c|c|c|c|}
\hline Term & $P$ value & Benjamini & FDR \\
\hline \multicolumn{4}{|l|}{ Spermatozoa } \\
\hline Spermatogenesis & 9.7E-9 & $4.8 \mathrm{E}-6$ & $1.4 \mathrm{E}-5$ \\
\hline Sperm motility & $9.6 \mathrm{E}-7$ & $2.4 \mathrm{E}-4$ & $1.4 \mathrm{E}-3$ \\
\hline Cell differentiation & $2.3 \mathrm{E}-5$ & $3.7 \mathrm{E}-3$ & 3.3E-2 \\
\hline $\begin{array}{l}\text { Multicellular organism } \\
\text { development }\end{array}$ & $1.4 \mathrm{E}-3$ & $1.5 \mathrm{E}-1$ & 2.0E0 \\
\hline $\begin{array}{l}\text { Cellular response to hormone } \\
\text { stimulus }\end{array}$ & $1.5 \mathrm{E}-3$ & $1.4 \mathrm{E}-1$ & 2.2E0 \\
\hline Lipid biosynthetic process & $2.1 \mathrm{E}-3$ & $1.5 \mathrm{E}-1$ & $2.9 \mathrm{E} 0$ \\
\hline Chromosome condensation & $2.7 \mathrm{E}-3$ & $1.7 \mathrm{E}-1$ & $3.8 \mathrm{E} 0$ \\
\hline Penetration of zona pellucida & $3.4 \mathrm{E}-2$ & $8.8 \mathrm{E}-1$ & $3.9 \mathrm{E} 1$ \\
\hline Fatty acid metabolic process & $4.1 \mathrm{E}-2$ & $9.0 \mathrm{E}-1$ & $4.5 \mathrm{E} 1$ \\
\hline Intracellular signal transduction & $4.6 \mathrm{E}-2$ & $9.0 \mathrm{E}-1$ & $4.9 \mathrm{E} 1$ \\
\hline \multicolumn{4}{|l|}{ MII } \\
\hline Cell cycle & $1.6 \mathrm{E}-39$ & $1.2 \mathrm{E}-35$ & $3.1 \mathrm{E}-36$ \\
\hline Cell division & $5.1 \mathrm{E}-36$ & $1.9 \mathrm{E}-32$ & $1.0 \mathrm{E}-32$ \\
\hline Protein transport & $1.5 \mathrm{E}-35$ & $3.7 \mathrm{E}-32$ & $3.0 \mathrm{E}-32$ \\
\hline Mitotic nuclear division & 1.7E-29 & $3.1 \mathrm{E}-26$ & $3.3 \mathrm{E}-26$ \\
\hline DNA repair & $1.2 \mathrm{E}-26$ & 1.7E-23 & $2.3 \mathrm{E}-23$ \\
\hline mRNA processing & $8.8 \mathrm{E}-25$ & $1.1 \mathrm{E}-21$ & $1.7 \mathrm{E}-21$ \\
\hline $\begin{array}{l}\text { Cellular response to DNA } \\
\text { damage stimulus }\end{array}$ & $2.5 \mathrm{E}-23$ & $2.7 \mathrm{E}-20$ & $5.0 \mathrm{E}-20$ \\
\hline Transcription, DNA-templated & $4.5 \mathrm{E}-20$ & $4.2 \mathrm{E}-17$ & $8.9 \mathrm{E}-17$ \\
\hline RNA splicing & 2.0E-18 & 1.6E-15 & $3.9 \mathrm{E}-15$ \\
\hline Transport & $5.2 \mathrm{E}-18$ & $3.8 \mathrm{E}-15$ & $1.0 \mathrm{E}-14$ \\
\hline \multicolumn{4}{|l|}{ Zygotes } \\
\hline Cell cycle & $6.3 \mathrm{E}-43$ & $4.6 \mathrm{E}-39$ & $1.3 \mathrm{E}-39$ \\
\hline Cell division & $1.1 \mathrm{E}-39$ & $4 \mathrm{E}-36$ & $2.2 \mathrm{E}-36$ \\
\hline Protein transport & $4 \mathrm{E}-34$ & $9.6 \mathrm{E}-31$ & $7.8 \mathrm{E}-31$ \\
\hline Mitotic nuclear division & $2.9 \mathrm{E}-31$ & $5.2 \mathrm{E}-28$ & $5.7 \mathrm{E}-28$ \\
\hline DNA repair & 7.7E-29 & $1.1 \mathrm{E}-25$ & $1.5 \mathrm{E}-25$ \\
\hline $\begin{array}{l}\text { Cellular response to DNA } \\
\text { damage stimulus }\end{array}$ & $4.9 \mathrm{E}-23$ & $5.9 \mathrm{E}-20$ & 9.7E-20 \\
\hline mRNA processing & $8.2 \mathrm{E}-23$ & 8.5E-20 & $1.6 \mathrm{E}-19$ \\
\hline Transcription, DNA-templated & 8.9E-20 & $8.1 \mathrm{E}-17$ & $1.8 \mathrm{E}-16$ \\
\hline RNA splicing & 8.1E-19 & $6.6 \mathrm{E}-16$ & $1.6 \mathrm{E}-15$ \\
\hline $\begin{array}{l}\text { Regulation of transcription, } \\
\text { DNA-templated }\end{array}$ & 3.1E-15 & $2.3 \mathrm{E}-12$ & $6.2 \mathrm{E}-12$ \\
\hline \multicolumn{4}{|l|}{ MII Up } \\
\hline mRNA processing & $1.8 \mathrm{E}-5$ & 2.7E-2 & $3.0 \mathrm{E}-2$ \\
\hline $\begin{array}{l}\text { Positive regulation of } \\
\text { telomerase RNA }\end{array}$ & $1.6 \mathrm{E}-3$ & $7.0 \mathrm{E}-1$ & $2.6 \mathrm{E} 0$ \\
\hline Chromatin remodeling & $1.7 \mathrm{E}-3$ & $5.6 \mathrm{E}-1$ & 2.7E0 \\
\hline \multicolumn{4}{|l|}{ PCZ Up } \\
\hline Cell cycle & 0.000028 & 0.03 & 0.045 \\
\hline RNA splicing & 0.00042 & 0.2 & 0.67 \\
\hline Protein ubiquitination & $1.2 \mathrm{E}-3$ & $3.5 \mathrm{E}-1$ & $1.9 \mathrm{E} 0$ \\
\hline
\end{tabular}

RNA lists from each source (sperm, MII eggs and zygotes) and differentially expressed MII-Zygote genes flagged by EdgeR analysis (MII up and PCZ UP) were submitted to DAVID for ontological analysis. Bioprocesses are reported alongside uncorrected $P$ values, Benjamini corrected $P$ values and False Discovery Rates (FDRs).

where the absence of clearly defined peaks from $18 \mathrm{~S}$ and $28 \mathrm{~S}$ ribosomal RNAs (low RIN score) indicates corresponding absence of contaminating somatic cell RNA (Supplementary Fig. 1, see section on supplementary data given at the end of this article). As additional QC, Real-Time qPCR primers for the Melanoma-Associated Antigen D2 (Maged2) were used to confirm potential contaminating somatic cell RNA in these preparations (principally from Leydig and Sertoli cells; 
Chalmel et al. 2007). Only spermatozoal cDNAs shown to be free of genomic DNA and somatic RNA contamination were used for library construction.

Mouse eggs and zygotes were processed at the single cell level. Each cell was transferred by mouth pipette into lysis buffer, after being immersed in DPBS (LIFE Technologies) in a washing step containing $0.1 \%$ BSA (Sigma Aldrich). Following first and second strand synthesis and processing using the Ovation single cell RNA-Seq system (NuGEN), Illumina adaptor sequences were ligated to the sperm, egg and zygote cDNAs. Two rounds of library amplification were carried out and the fragment distribution was checked using the Agilent high sensitivity DNA assay on the 2100 Bioanalyser (Agilent Technologies). The libraries were quantified using Picogreen assay (Thermo Scientific) on a FLUOstar Galaxy plate reader (MTX Lab Systems, Bradenton, FL, USA) and pooled. The Illumina HiSeq 2500 and 3000 platforms were employed for RNA-Seq.

\section{Bioinformatics analysis}

Spermatozoa, MII eggs and zygotes from a minimum of three biological replicates each were sequenced using either $50 \mathrm{bp}$ (single-ended) or $150 \mathrm{bp}$ paired-end reads. RNA-Seq data underwent automated adapter and quality trimming using Trim Galore! v0.4, ignoring reads with MAPQ $<20$ (Krueger 2015). The filtered reads were mapped to the Mus musculus reference genome (mm10) using the subjunc function of the Rsubread package version 1.20.3 (Liao et al. 2013b). The output BAM format files were sorted using Samtools version 1.3 ( $\mathrm{Li}$ et al. 2009) and duplicate reads removed using the Picard MarkDuplicates tool version 2.1.1 (Broad Institute (2010), available online at http://broadinstitute.github.io/picard). BedGraph and bigwig files were generated using Bedtools version 2.25.0 (Quinlan \& Hall 2010), and the function bedGraphToBigWig (http://hgdownload.soe.ucsc.edu/admin/ exe/macOSX.x86_64/bedGraphToBigWig). After removal of duplicate unmapped and incorrectly paired reads using Samtools version 1.3 (Li et al. 2009), the reads were visualized on the UCSC genome browser (Kent et al. 2002). The numbers of reads assigned to genomic features were counted using the featureCounts function of Rsubread (Liao et al. 2013a). For paired-end libraries, we required both read mates to be uniquely mapped in the correct orientation. All remaining options were set to featureCounts default. Differential RNA representation in MII egg and zygote RNA-Seq libraries was tested using the edgeR exact test (Robinson et al. 2010) and only genes represented at levels $\geq 10$ counts-per-million reads (CPM) in at least 6 out of $7 \mathrm{MII}$ and zygote libraries were included in the downstream analysis. The only exception to this rule was for five maternal transcripts with reads just below $10 \mathrm{CPM}$, represented across all exons, that were also included. Data normalisation was based on the trimmed mean of $M$ value (TMM) using the calcNormFactorsfunction (Robinson \& Oshlack 2010).

\section{Ontological analysis, gene networks and molecular interactions}

Ontological descriptions of RNAs from sperm, MII eggs and zygotes were derived by DAVID v6.8 (Huang et al. 2009), with a subsequent focus on biological processes. Gene networks involving candidate spermatozoal and maternal factors were identified by the Cytoscape module GeneMANIA v.3.4.1; (Warde-Farley et al. 2010). GeneMANIA uses publically available data sets, encompassing physical and molecular interactions, co-expression, co-localisation and molecular pathways.

\section{NGS validation using quantitative real-time PCR}

Following first-strand cDNA synthesis, the cDNA of mouse MII egg, zygote, spermatozoal and testicular RNA (positive control) was amplified by long distance PCR, using the SMART-Seq v4 ultra low input RNA kit (Clontech). Validatory quantitative real-time PCR was carried out as required using gene-specific primers (Supplementary Table 1) and SYBR green on an ABI 7900HT Real-time PCR system (Applied Biosystems) over 40 cycles according to the manufacturer's instructions. The annealing temperature per primer pair ranged between $59^{\circ} \mathrm{C}$ and $62^{\circ} \mathrm{C}$.

Table 2 Paternally-derived factors and their potential maternal cofactors in Mus musculus.

\begin{tabular}{|c|c|c|c|}
\hline Spermatozoal gene & $\begin{array}{l}\text { Associated gene name and MGI accession } \\
\text { number }\end{array}$ & Function (UniProt) & $\begin{array}{l}\text { Potential maternal } \\
\text { interactions (GeneMANIA) }\end{array}$ \\
\hline FbxO2 & $\begin{array}{l}\text { F-Box Protein } 2 \text { (Source: MGI Symbol; Acc: } \\
\text { MGI:2446216) }\end{array}$ & $\begin{array}{l}\text { Component of E3 ubiquitin-protein ligase } \\
\text { SCF (SKP1-CUL1-F-box protein) complex }\end{array}$ & $\begin{array}{l}\text { Cul1, FbxI2, Fbx/3, Fbxl5, } \\
\text { Fbxo34, Fbxo5, Itgb1, } \\
\text { Rbx1, Skp1a }\end{array}$ \\
\hline Map 1/с3а & $\begin{array}{l}\text { Microtubule-associated protein } 1 \text { light chain } 3 \\
\text { alpha (Source: MGI Symbol; Acc: } \\
\text { MGI:1915661) }\end{array}$ & $\begin{array}{l}\text { Ubiquitin-like protein involved in } \\
\text { autophagosome formation }\end{array}$ & $\begin{array}{l}\text { Atg10, Atg3, Gabarap/2, } \\
\text { Kif15, Map1b, Map1/c3b, } \\
\text { Pias4, Tubb2a, Wdfy3 }\end{array}$ \\
\hline Pcbp4 & $\begin{array}{l}\text { Poly(rC) binding protein } 4 \text { (Source: MGl } \\
\text { Symbol; Acc: MGI:1890471) }\end{array}$ & $\begin{array}{l}\text { Binds to single stranded nucleic acids and } \\
\text { specifically to oligo }(\mathrm{dC})\end{array}$ & Pcbp 1, Pcbp2, Qk, Hnrnpk \\
\hline Zfp821 & $\begin{array}{l}\text { Zinc finger protein } 821 \text { (Source: MGI Symbol; } \\
\text { Acc: MGI:1923121) }\end{array}$ & $\begin{array}{l}\text { Maybe involved in transcription regulation } \\
\text { through DNA binding }\end{array}$ & $\begin{array}{l}\text { Aggf1, Chchd3, Fam 13c, } \\
\text { Fchsd2, Mob1a, Rimklb, } \\
\text { Tspyl4, Zfc3h1 }\end{array}$ \\
\hline Hdac11 & $\begin{array}{l}\text { Histone deacetylase } 11 \text { (Source: MGI Symbol; } \\
\text { Acc: MGI:2385252) }\end{array}$ & $\begin{array}{l}\text { Deacetylates core histones and plays a role } \\
\text { in transcription regulation, cell cycle, } \\
\text { epigenetic repression and development }\end{array}$ & $\begin{array}{l}\text { Aamp, Bub1b, Cdc20, } \\
\text { Hdac2, Hdac8, Mett/18, } \\
\text { Nelfcd }\end{array}$ \\
\hline
\end{tabular}

Column 1 shows spermatozoal factors with good exonic representation as revealed by RNA-Seq and UCSC browsing. Column 2 gives the associated gene name and MGl accession number. Column 3 briefly depicts their functionality as described in UniProt. Column 4 shows the potentially interacting maternal factors as predicted by GeneMANIA. 




Figure 2 GeneMANIA network nodes. The nodes represent paternal (blue) and maternal (black) factors and their predicted interactions (interconnecting lines). Colours signify the interaction type including co-expression (purple), physical interactions (red), shared protein domains (green), co-localisation (blue) and all predicted interactions (orange). Nodes with boxes around them belong to the E3 ubiquitin ligase complex. Other encircling borders indicate additional inter-parental interactions supported by the RNA-seq data (see text for details).

\section{Results}

\section{RNA characterisation and ontological profiles}

The average correctly paired and mapped reads per sperm RNA sample was calculated at $20 \pm 2 \times 10^{6}$. The average number for MII eggs was $18 \pm 1.5 \times 10^{6}$ and for the zygotes $20 \pm 1.5 \times 10^{6}$ per sample. RefSeq IDs for sperm, MII eggs and zygotes, alongside differentially expressed RNAs using EdgeR for MIl eggs and zygotes are listed in the Supplementary data (RNA lists). While we cannot be certain that RNAs common to sperm and zygotes originated in the fertilising sperm, our initial approach was to look for sperm RNAs that were absent in MII eggs but present in zygotes. Figure 1A shows Venn diagrams for overlaps between sperm, MII egg and zygote RNAs $\geq 10$ CPM. In aggregate, 5368, 5148 and 1918 RNAs were reported, respectively from MII eggs, zygotes and sperm with 75 shared between sperm and zygotes that were either absent altogether or present in MII eggs at well below threshold reporting levels. The same sperm list compared with EdgeR normalised reads for MII egg and zygote RNAs yielded 56 RNAs shared between sperm and zygotes (Fig. 1B). Closer scrutiny of the read data, however, showed all but four of these 'shared' RNAs were detected in MII eggs albeit at low levels of expression (<10CPM). The four absent in MII eggs were more fragmented in sperm than in zygotes, suggesting they were not sperm-specific.

An alternative approach focused simply on highly abundant sperm RNAs with good exon coverage that were essentially absent in both MII eggs and zygotes. To help narrow down the list of hundreds of possible RNAs to pursue in this regard, functional annotation clustering
(Supplementary data; FAC sheets) was employed to provide a general overview of MII egg and zygote RNAs using the lists of differentially expressed MII egg and zygote RNAs generated by EdgeR alongside the list of sperm RNAs selected on the basis of high representation and good exon coverage. A graphical representation of the numbers of genes in the main ontological annotations (biological processes) for sperm, MII eggs and zygotes is shown in Supplementary Fig. 2.

As shown in Table 1 and in Supplementary data (BP; EdgeR sheet), the expected top sperm annotation related to spermatogenesis as a differentiation process, with associated weaker enrichments in processes associated with lipid metabolism and DNA condensation. Enrichment for annotation relating to the control of transcription dominated the ontological descriptions for both MII eggs and zygotes, which was expected considering the similarity between them (Table 1 and Supplementary data; BP EdgeR sheet). Focusing on differential expression between the two, however, revealed interesting differences (Supplementary data; BP EdgeR MII or PCZ Up sheet). MII eggs showed specific enrichments in activities relating to mRNA processing, while the cell cycle showed the strongest enrichment in zygotes. Processes relating to ubiquitination and transcription were more apparent in differentially up-regulated RNAs from zygotes but not MII eggs, suggesting that clearance activity and perhaps renewed RNA processing triggered by fertilisation may have already commenced in zygotes at the time of harvesting.

Using the functional annotation of highly expressed RNAs as guidance alongside closer inspection of the selected gene lists from sperm, MII eggs and zygotes, 


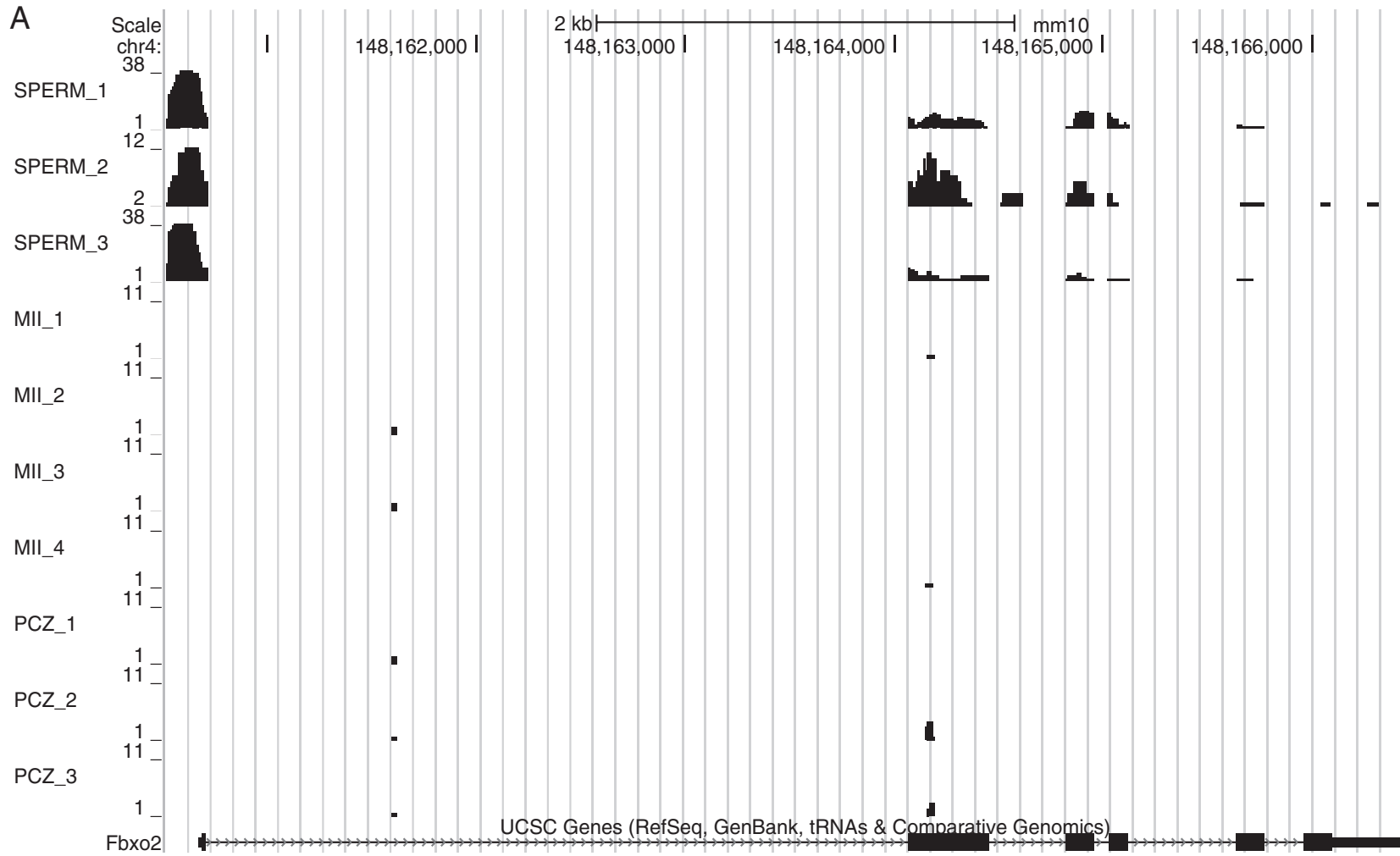

B

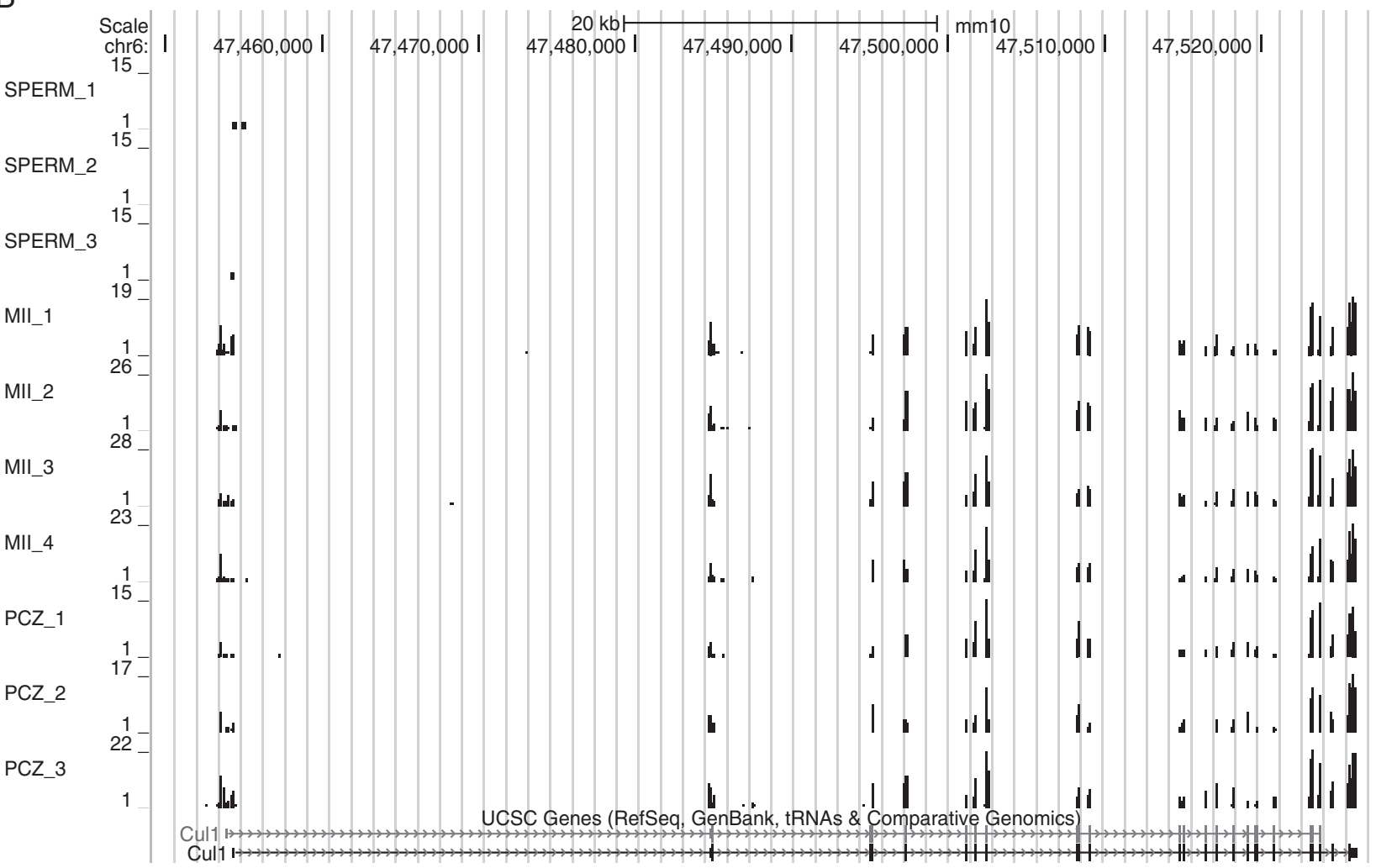

Figure 3 Continued. 


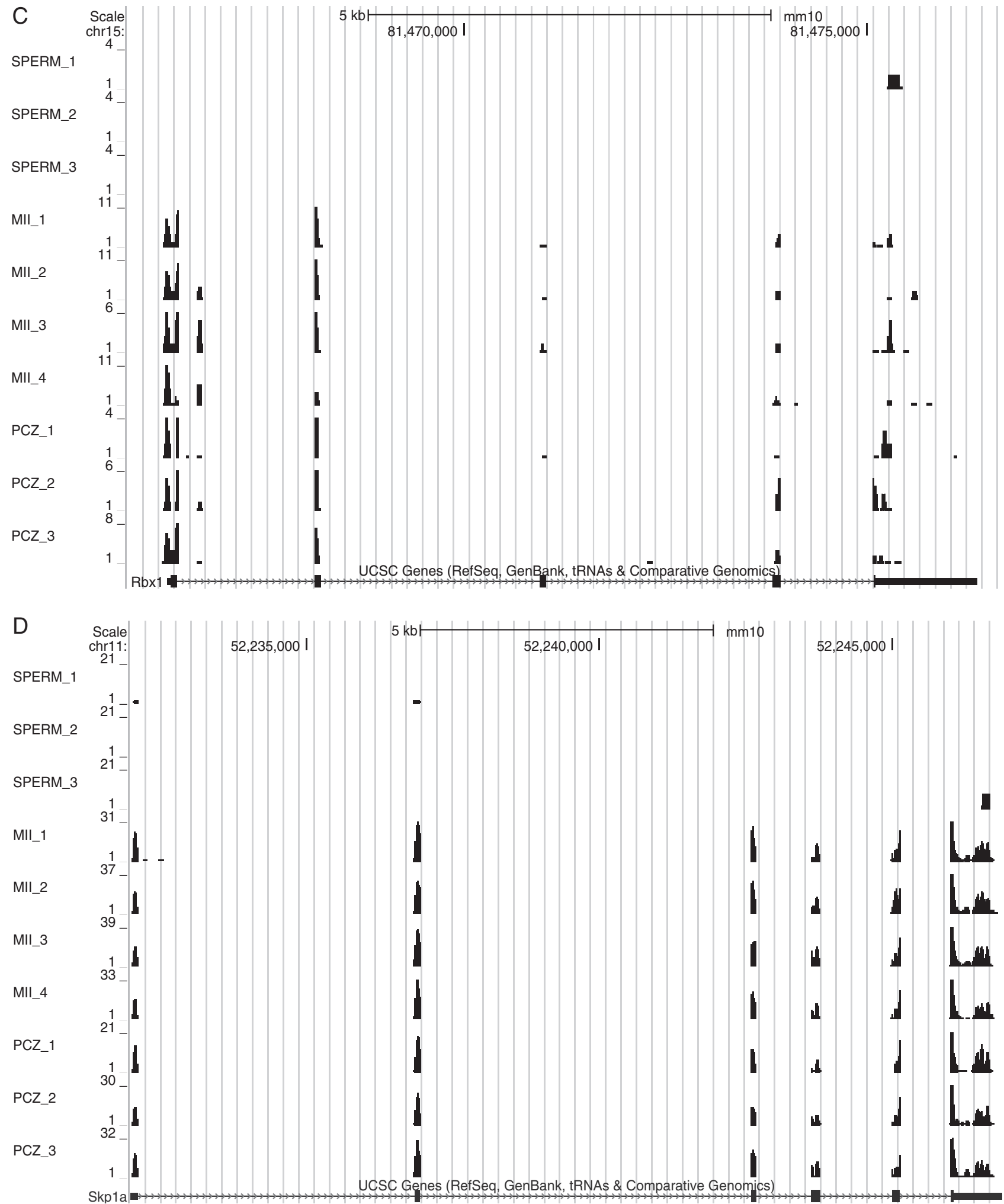

Figure 3 Alignment of RNA sequencing reads (pile ups) across representative components of the E3 ubiquitin ligase complex. As tracked on the UCSC genome browser for all spermatozoal (sperm 1-3), egg (MII 1-4) and zygote (PCZ 1-3) biological replicates, reads for components of the


diagram with exons shown as filled blocks. 
A


B 35

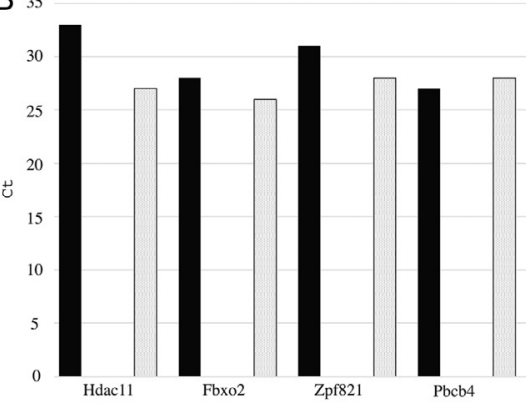

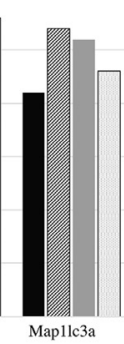

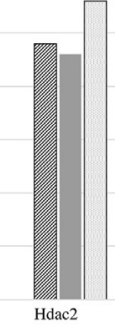

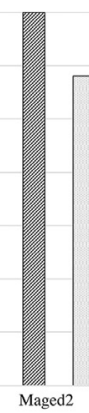

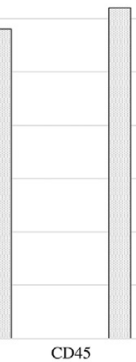

Figure 4 Real-time qPCR. Real-time qPCR was carried out on $400 \mathrm{pg}$ of cDNA using primers for the five RNA-seq predicted paternal factors Hdac11, Fbxo2, Zfp821, Pcbp4 and Map 1/c3a, the maternal Hdac2 and the testis-expressed somatic cell RNA control Maged2. QPCR products are shown for sperm (S), MIl eggs (M), Zygotes (Z) and Testis (T) cDNAs in panel A with corresponding $\mathrm{Ct}$ values shown in panel B. A DNA ladder is shown for gel calibration with $100 \mathrm{bp}$ and $500 \mathrm{bp}$ markers indicated. Note that very high Ct values ( $>37$ ) corresponding with samples not supporting specific PCR products and assumed to be PCR artifacts are plotted as 0 . potential interacting partners relating to clearance of maternal factors were revealed. Considering the RNAs' high expression in sperm compared with MII eggs and zygotes, their exclusion from the dominant spermatogenesis ontology and their relative freedom from fragmentation as assessed by exon coverage, five sperm RNAs were selected for follow up (Table 2). These include the histone deacetylase 11 (Hdac11), the Rbx1-SCF E3 ubiquitin-ligase component F-box protein 2 (Fbxo2), the microtubule-associated protein 1A/1B light chain 3A (Map1/c3a), the poly ( $\mathrm{rC}$ )-binding protein 4 (Pcbp4) and the zinc finger protein 821 (Zfp821). These five sperm RNAs were in turn interrogated using GeneMANIA for all known interacting partners, which returned approximately 100 genes of which 37 were either present in the up-regulated zygotic transcripts or in the list of shared (MII \& zygote) maternal RNAs (Table 2). Together, these paternal and maternal RNAs comprise the gene network profile shown in Fig. 2. The network's functional annotation was dominated by strong enrichment in processes related to ubiquitinmediated degradation pathways (Supplementary data; BP EdgeR sheet), reflecting the ontology of up-regulated transcripts in zygotes.

\section{Predicting and providing evidence for potential parental interactions}

Network analysis (Fig. 2) suggested that paternal ( $\left.0^{*}\right)$ and maternal (o) cofactors could interact in pathways leading to EZT. An example is illustrated in Fig. 3 for the gamete-specific cofactors of the multiple component SCF E3 ubiquitin ligase complex which includes Fbxo2 (also known as Fbs 10; A) alongside Cullin 1 (Cul1o; B), Ring Box 1 (Rbx1\%; C) and S-Phase Kinase-Associated Protein 1A (Skp1aq; D). These genes are indicated in Fig. 2 by boxes. Note that reads covering all exons for Fbxo2, were strongly represented in the sperm RNA libraries but with few or no reads from either MII egg or zygote libraries. In contrast, with the exception of Fbxo2, RNAs encoding the other cofactors of the SCFE3 ubiquitin ligase complex were highly represented in both MII eggs and zygotes but not in sperm. Additional predicted interactions between $\mathrm{FbxO} 2 \mathrm{O}^{\star}$ and the maternally expressed Fbxo5o and Fbxo34우 were also suggested (Fig. 2 and Table 2; boxes). Real-time qPCR confirmed the expression of paternal factors in sperm and testis (Fig. 4) and although products were generated for Map1 lc3a from all sources (panel A), Ct data confirmed that the RNA was considerably more abundant in sperm (see panel B). A 142 bp product from Maged 2 was only detected in RNA from eggs and testis, indicating that sperm libraries were free of contamination by RNAs from testis-derived somatic cells. All PCR products were obtained from samples after 40 PCR cyles and so the products shown in panel $\mathrm{A}$ are only qualitative. The corresponding $\mathrm{Ct}$ values give more quantitative assessments.

UCSC tracks are shown in Supplementary Fig. 3 for a number of additional, GeneMANIA suggested potential paternal-maternal interacting cofactors. Hdac11 $\delta^{-}(\mathrm{A})$, which was highly expressed in sperm, could interact 


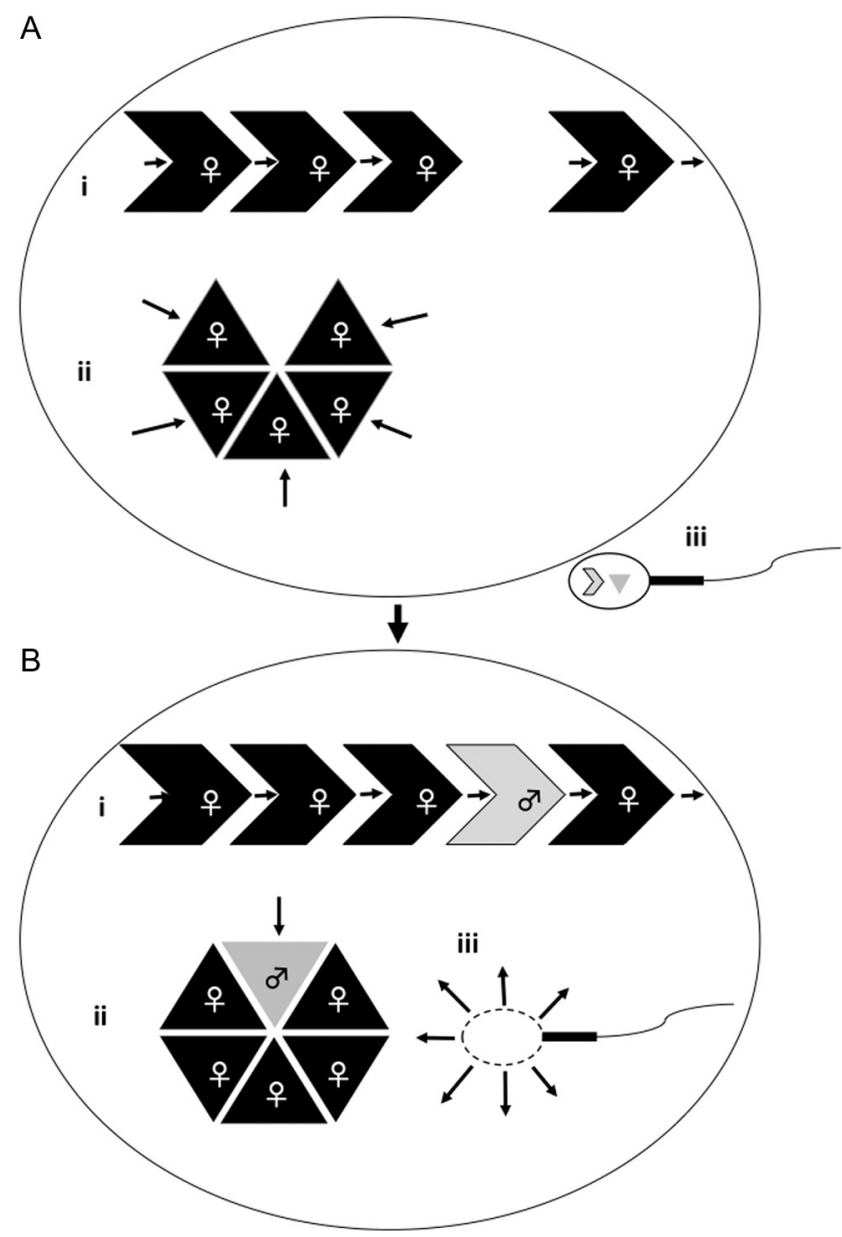

Figure 5 Alternative potential pathways for a paternal contribution to the zygote. The first panel (A) depicts the MII egg and the spermatozoon just before fertilisation with (i) a metabolic pathway that needs one or more paternal factors to be fulfilled (either RNA or protein); (ii) a protein complex that needs a paternal factor to be functional; (iii) the incoming fertilizing spermatozoon. The second panel (B) depicts the MII egg and spermatozoon after fertilization with, (i) a functional metabolic pathway following the insertion of a paternal factor; (ii) an activated protein complex due to the addition of the missing paternal factor, such as Fbxo2 in the Rbx1-E3 ubiquitin ligase. The disintegrating sperm membrane with arrows illustrating the released sperm-borne factors into the MII ooplasm is also shown (iii).

with the Mitotic Checkpoint Serine/Threonine Kinase B, (Bub1\%; B) and cell division cycle protein 20 (Cdc20\%; Fig. 2; ovals). GeneMANIA also suggested potential co-localisation and co-expression between Hdac110, Hdac2o and Hdac8 (Fig. 2; ovals) with Hdac110 and Hdac2o having shared protein domains. Predicted interactions with the Nelfcdo and Aampo were also highlighted (Fig. 2; ovals). Reads from a long terminal repeat $\left(\mathrm{LTR}^{\boldsymbol{}}{ }^{\mathrm{B}}\right)$ region located within the 8th intron of Hdac11, which could potentially be expressed independently of Hdac110 RNA were also noted (Supplementary Fig. 3A).
The ubiquitin-like protein Microtubule Associated protein 1, light chain 3 alpha (Map1/c3aó; C) is involved in autophagosome formation and GeneMania indicated functional interactions with several maternal factors, including Map1bo (D), Atg3우 (E) and Atg10우 (Fig. 2, boxes with course dashed lines) of which Atg3우 and Map1bo showed high levels of expression in MII eggs and zygotes with good exonic representation and were absent in sperm. In addition, Pcbp4o (F), which may complement the heterogeneous nuclear ribonucleoprotein $\mathrm{K}$ (Hnrnpko; G) and Quaking ( $Q k \%$; $\mathrm{H}$; and Fig. 2, pentangles) were highly represented in MII eggs and zygotes but not in sperm. The corresponding maternal proteins are involved in post-transcriptional regulation of gene expression, protein degradation and the cell cycle. Pcbp4 $0^{\star}$ also has predicted interactions with Pcbp1\% and co-localises with the Pcbp2o isoform. Finally, GeneMANIA reported predicted interactions between Zfp8210 (I), which may be involved in transcriptional regulation, Fchsd2o and Rimlkbo (Fig. 2; boxes with fine dashed lines). Zpf8210 is highly expressed in sperm but not MII eggs and zygotes.

\section{Discussion}

Existing sequencing germ line and zygote datasets are not fully complementary and are therefore difficult to compare(theyeitheromitspermorMlleggsor zygotesfrom their analysis) and are derived from library construction methods that differ between the various cell types (Tang et al. 2010, Xue et al. 2013, Johnson et al. 2015). To avoid introducing methodological effects and bias, we used a bespoke pipeline that included construction of our own libraries for sequencing and analysis. Sperm contain far less RNA than either MII eggs or zygotes; therefore, sperm libraries were unavoidably derived from sperm-specific pooled samples while MII egg and zygote libraries were from individual cells. The equivalent read counts obtained from the three sources demonstrate the care taken to assure quantitative equivalence of input RNA. We found, however, that relying on comparisons between the three to select sperm-specific factors were problematic, because although representation may have been too low to report the RNA as present in MII eggs or zygotes (for example), we frequently encountered reads indicating fragmented RNA in both regardless. We focused, therefore, on highly abundant RNAs with fulllength transcripts in sperm, MII eggs and zygotes and with demonstrably reciprocal representation (in sperm but not MII eggs or zygotes and the reverse) following inspection of RNA-Seq tracks on the UCSC browser and where necessary, confirming by qRT-PCR.

In silico analysis of our RNA sequencing data supports the possible complementation of maternal with paternal factors introduced at fertilization. Five highly expressed sperm RNAs were considered based 
on their relative low abundance or absence in MII eggs or zygotes. All factors potentially interacting with translated products from these RNAs were mapped out using the pathway and network analyses tools in GeneMANIA. These factors were then matched to corresponding maternal cofactors to help identify those with a greater potential to participate in EZT pathways. As the predicted interactions were more likely to be between proteins, where possible we checked for a corresponding proteomic record of the RNAs in question (Wang et al. 2010, 2013, Skerget et al. 2015). Sperm RNAs could either be translated into proteins during late spermatogenesis or if delivered to the MII egg, in the pre cleavage stage zygote (Fang et al. 2014). We also searched for reproductive effects of existing knockout models for the corresponding genes of parental factors where available (Supplementary Table 2).

The current study provides evidence of a novel role for paternally introduced factors in murine zygotic RNA/ protein clearance (Stitzel \& Seydoux 2007, Sato \& Sato 2013). The RBX1-SCFE3 ubiquitin ligase complex, for example, plays an important role during gametogenesis and mouse embryogenesis, catalysing the ubiquitination of proteins during cytoplasmic turnover, which are then destined for proteasomal degradation (Jia \& Sun 2009, Sato \& Sato 2013). The F-box family includes FBXO2, which is an E3 ligase adaptor protein targeting glycosylated proteins for degradation. Our network analysis, showed that all RBX1-SCF E3 ubiquitin ligase components but one (Fbxo2 $\sigma^{\star}$ ) were maternally expressed (McCall et al. 2005) and on fertilisation, $\mathrm{FBXO} 2{ }^{\star}$ could complete the complex and be active in the EZT. The FBXO2 protein is also present in mature sperm (Wang et al. 2013) and has been linked to idiopathic male infertility (Bieniek et al. 2016). Similarly, MAP1LC3A ${ }^{*}$ is a ubiquitin-like modifier (Cherra et al. 2010) with potential autophagic interactions with ATG39 and MAP1Bo. MAP1B protein is also present in eggs and zygotes. Both Atg3 and Map 1b KO studies show lethality one day after birth (Supplementary Table 2).

Quaking (QK)Q, HNRNPKO and PCBP1/2/4Q/ð showed predicted in silico interactions as part of the post-transcription regulatory process. In C. elegans, the first wave of degradation of egg factors involves PES4 (Stoeckius et al. 2014a), a member of the PCBP family of RNA-binding proteins that post-transcriptionally regulate alternative polyadenylation at a global level (Ji et al. 2013). Both members of the Poly-(rC) binding protein family, PCBP4 0 and PCBP1/2\%, detected in our analysis, are mammalian orthologues of the nematode PES4 protein. Potential interactions between HDAC11 0 , BUB1Bo and CDC20 were predicted by our analysis and both $\mathrm{Hdac} 11$ and $B u b 1 \mathrm{~b}$ were detected in high levels in sperm and eggs/zygotes, respectively. HDAC110 is involved in epigenetic repression, transcriptional regulation and embryonic development (Haberland et al. 2009, Bagui et al. 2013, Sahakian et al. 2015).
HDAC11 activates BUB1B by deacetylation, which in turn lifts the inhibition of the CDC20/APC complex, activating its ubiquitin ligase activity (Watanabe 2014). Although the fertility rate of mice homozygous for Hdac11 deletion has not been reported, Cdc20 KO mice showed 2-cell embryo arrest and Bub1b KO mice show developmental arrest in early gestation (E8.5) (Supplementary Table 2).

A particularly interesting finding was the expression of a long terminal repeat (LTR) transposable element, located entirely within the 8th intron of Hdac11 (intragenic) in sperm, which was absent in both MII eggs and zygotes. LTR RNAs are expressed abundantly in mouse eggs and zygotes where they are thought to augment the regulation of host gene expression (Peaston et al. 2004, Göke et al. 2015). Spermatozoal LTRs transferred into the oocyte during fertilization, could lead to new retrotransposition events and possibly genetic alterations (Kitsou et al. 2016). Paternally derived Hdac11 LTRs may have maternal targets that together participate in the regulation of zygotic gene expression.

In conclusion, our data support the argument favouring extra-genomic contributions by the fertilising sperm to the zygote. In addition to the inheritance of acquired traits propagating transgenerationally via sperm RNA (Gapp et al. 2014, Chen et al. 2016), our data and its analysis provide evidence for a role of paternal RNAs or proteins in maternal clearance during EZT. Sperm may deliver signals or factors that can potentially interact locally with maternal cofactors and act, perhaps as a 'last minute' checkpoint or gateway for embryonic genome activation (EGA). The hypothesis of confrontation and consolidation with regard to the uniquely invasive nature of sperm entry to the egg falls into this latter category (Miller 2015, Bourc'his \& Voinnet 2010). Figure 5 shows a model for how a sperm factor introduced at fertilisation might complement a maternal cofactor or pathway required for the EZT. At least one such sperm-borne factor, PLC zeta ${ }^{*}$ is already known to activate the oocyte (Saunders et al. 2002). A similar approach to ours could be employed to investigate paternal/maternal interactions in humans. However, to confirm the potential biological relevance of the suggested interacting cofactors reported in this study, additional work such as RNA knock down upon or conditional gene knock out prior to fertilization would require the mouse model. In view of the renewed concern over rising human male infertility (Levine 2017) and the rapid rise and expansion of infertility treatment by ICSI, further research into extra-genomic paternal contributions using model systems is fully justified.

\section{Supplementary data}

This is linked to the online version of the paper at http://dx.doi.org/10.1530/REP-17-0097. 


\section{Declaration of interest}

The authors declare that they have no conflict of interest that could be perceived as prejudicing the impartiality of the research reported.

\section{Funding}

This work was supported by a FP7, Marie Curie International Reproductive Biology Early Research Training (Reprotrain) network fellowship to Panagiotis Ntostis (Grant number 289880, 2012). P Ntostis carried out the experimental work and wrote the original manuscript, and P Ntostis and D Iles carried out the bioinformatic analysis reported in this paper. D Carter assisted with the animal work, J Huntriss and M Tzetis provided critical reading of the manuscript and D Miller and D Iles designed the original experimental plan and D Miller revised and wrote the final manuscript.

\section{References}

Bagui TK, Sharma SS, Ma L \& Pledger WJ 2013 Proliferative status regulates HDAC11 mRNA abundance in nontransformed fibroblasts. Cell Cycle 12 3433-3441. (doi:10.4161/cc.26433)

Barroso G, Valdespin C, Vega E, Kershenovich R, Avila R, Avendano C \& Oehninger S 2009 Developmental sperm contributions: fertilization and beyond. Fertility and Sterility 92 835-848. (doi:10.1016/j. fertnstert.2009.06.030)

Bieniek JM, Drabovich AP \& Lo KC 2016 Seminal biomarkers for the evaluation of male infertility. Asian Journal of Andrology $\mathbf{1 8} 426$. (doi:10.4103/1008-682X.175781)

Bourc'his D \& Voinnet O 2010 A small-RNA perspective on gametogenesis, fertilization, and early zygotic development. Science 330 617-622. (doi:10.1126/science.1194776)

Braun RE 2000Temporal control of protein synthesis during spermatogenesis. International Journal of Andrology 23 92-94. (doi:10.1046/j.13652605.2000.00027.x)

Chalmel F, Rolland AD, Niederhauser-Wiederkehr C, Chung SS, Demougin P, Gattiker A, Moore J, Patard J-J, Wolgemuth DJ \& Jégou B 2007 The conserved transcriptome in human and rodent male gametogenesis. PNAS 104 8346-8351. (doi:10.1073/pnas.0701883104)

Chen Q, Yan W \& Duan E 2016 Epigenetic inheritance of acquired traits through sperm RNAs and sperm RNA modifications. Nature Reviews Genetics 17 733-743. (doi:10.1038/nrg.2016.106)

Cherra SJ, Kulich SM, Uechi G, Balasubramani M, Mountzouris J, Day BW \& Chu CT 2010 Regulation of the autophagy protein LC3 by phosphorylation. Journal of Cell Biology 190 533-539. (doi:10.1083/ jcb.201002108)

Evsikov AV, Graber JH, Brockman JM, Hampl A, Holbrook AE, Singh P, Eppig JJ, Solter D \& Knowles BB 2006 Cracking the egg: molecular dynamics and evolutionary aspects of the transition from the fully grown oocyte to embryo. Genes and Development 20 2713-2727. (doi:10.1101/gad.1471006)

Fang P, Zeng P, Wang Z, Liu M, Xu W, Dai J, Zhao X, Zhang D, Liang D, Chen X et al. 2014 Estimated diversity of messenger RNAs in each murine spermatozoa and their potential function during early zygotic development. Biology of Reproduction 90 94. (doi:10.1095/ biolreprod.114.117788)

Fourie J, Loskutoff N \& Huyser C 2012 Elimination of bacteria from human semen during sperm preparation using density gradient centrifugation with a novel tube insert. Andrologia 44 513-517. (doi:10.1111/j.14390272.2011.01217.x)

Gapp K, Jawaid A, Sarkies P, Bohacek J, Pelczar P, Prados J, Farinelli L, Miska E \& Mansuy IM 2014 Implication of sperm RNAs in transgenerational inheritance of the effects of early trauma in mice. Nature Neuroscience 17 667-669. (doi:10.1038/nn.3695)
Giraldez AJ 2010 microRNAs, the cell's Nepenthe: clearing the past during the maternal-to-zygotic transition and cellular reprogramming. Current Opinion in Genetics and Development 20 369-375. (doi:10.1016/j. gde.2010.04.003)

Göke J, Lu X, Chan Y-S, Ng H-H, Ly L-H, Sachs F \& Szczerbinska I 2015 Dynamic transcription of distinct classes of endogenous retroviral elements marks specific populations of early human embryonic cells. Cell Stem Cell 16 135-141. (doi:10.1016/j.stem.2015.01.005)

Goodrich RJ, Anton E \& Krawetz SA 2013 Isolating mRNA and small noncoding RNAs from human sperm. Spermatogenesis: Methods and Protocols 927 385-396. (doi:10.1007/978-1-62703-038-0_33)

Gurdon JB \& Melton DA 2008 Nuclear reprogramming in cells. Science 322 1811-1815. (doi:10.1126/science.1160810)

Haberland M, Montgomery RL \& Olson EN 2009 The many roles of histone deacetylases in development and physiology: implications for disease and therapy. Nature Reviews Genetics 10 32-42. (doi:10.1038/ nrg2485)

Huang DW, Sherman BT \& Lempicki RA 2009 Systematic and integrative analysis of large gene lists using DAVID bioinformatics resources. Nature Protocols 4 44. (doi:10.1038/nprot.2008.211)

Ji X, Wan J, Vishnu M, Xing Y \& Liebhaber SA 2013 жCP poly (C) binding proteins act as global regulators of alternative polyadenylation. Molecular and Cellular Biology 33 2560-2573. (doi:10.1128/MCB.01380-12)

Jia L \& Sun Y 2009 RBX1/ROC1-SCF E3 ubiquitin ligase is required for mouse embryogenesis and cancer cell survival. Cell Division 416. (doi:10.1186/1747-1028-4-16)

Jodar M, Sendler E, Moskovtsev SI, Librach CL, Goodrich R, Swanson S, Hauser R, Diamond MP \& Krawetz SA 2015 Absence of sperm RNA elements correlates with idiopathic male infertility. Science Translational Medicine 7 295re296. (doi:10.1126/scitranslmed.aab1287)

Johnson GD, Mackie P, Jodar M, Moskovtsev S \& Krawetz SA 2015 Chromatin and extracellular vesicle associated sperm RNAs. Nucleic Acids Research 43 6847-6859. (doi:10.1093/nar/gkv591)

Kent WJ, Sugnet CW, Furey TS, Roskin KM, Pringle TH, Zahler AM \& Haussler D 2002 The human genome browser at UCSC. Genome Research 12 996-1006. (doi:10.1101/gr.229102)

Kitsou C, Lazaros L, Bellou S, Vartholomatos G, Sakaloglou P, Hatzi E, Markoula S, Zikopoulos K, Tzavaras T \& Georgiou I 2016 Exogenous retroelement integration in sperm and embryos affects preimplantation development. Reproduction 152 185-193. (doi:10.1530/REP-150174)

Kono T, Obata Y, Wu Q, Niwa K, Ono Y, Yamamoto Y, Park ES, Seo J-S \& Ogawa H 2004 Birth of parthenogenetic mice that can develop to adulthood. Nature 428 860-864. (doi:10.1038/nature02402)

Krueger F 2015 Trim Galore!: a wrapper tool around Cutadapt and FastQC to consistently apply quality and adapter trimming to FastQ files.

Lee MT, Bonneau AR \& Giraldez AJ 2013 Zygotic genome activation during the maternal-to-zygotic transition. Annual Review of Cell and Developmental Biology 30 581-613. (doi:10.1146/annurevcellbio-100913-013027)

Levine $\mathrm{H}$, Jørgensen, N, Martino-Andrade A, Mendiola J, Weksler-Derri D, Mindlis I, Pinotti R \& Swan R 2017 Temporal trends in sperm count: a systematic review and meta-regression analysis. Human Reproduction Update.

Li H, Handsaker B, Wysoker A, Fennell T, Ruan J, Homer N, Marth G, Abecasis G \& Durbin R 2009 The sequence alignment/map format and SAMtools. Bioinformatics 25 2078-2079. (doi:10.1093/bioinformatics/ btp352)

Liao Y, Smyth GK \& Shi W 2013a FeatureCounts: an efficient general purpose program for assigning sequence reads to genomic features. Bioinformatics 30 923-930. (doi:10.1093/bioinformatics/btt656)

Liao Y, Smyth GK \& Shi W 2013b The subread aligner: fast, accurate and scalable read mapping by seed-and-vote. Nucleic Acids Research 41 e108-e108. (doi:10.1093/nar/gkt214)

Marlow FL 2010. Maternal Control of Development in Vertebrates, pp 1-196. Morgan \& Claypool Life Sciences, San Rafael, California (USA).

McCall CM, Hu J \& Xiong Y 2005 Recruiting substrates to cullin 4-dependent ubiquitin ligases by DDB1. Cell Cycle 4 27-29. (doi:10.4161/cc.4.1.1396)

Miller D 2015 Confrontation, consolidation, and recognition: the oocyte's perspective on the incoming sperm. Cold Spring Harbor Perspectives in Medicine 5 a023408. (doi:10.1101/cshperspect.a023408) 
Ostermeier GC, Miller D, Huntriss JD, Diamond MP \& Krawetz SA 2004 Reproductive biology: delivering spermatozoan RNA to the oocyte. Nature 429 154. (doi:10.1038/429154a)

Paranjpe SS, Jacobi UG, van Heeringen SJ \& Veenstra GJC 2013 A genomewide survey of maternal and embryonic transcripts during Xenopus tropicalis development. BMC Genomics 14 762. (doi:10.1186/14712164-14-762)

Peaston AE, Evsikov AV, Graber JH, De Vries WN, Holbrook AE, Solter D \& Knowles BB 2004 Retrotransposons regulate host genes in mouse oocytes and preimplantation embryos. Developmental Cell 7 597-606. (doi:10.1016/j.devcel.2004.09.004)

Potireddy S, Vassena R, Patel BG \& Latham KE 2006 Analysis of polysomal mRNA populations of mouse oocytes and zygotes: dynamic changes in maternal mRNA utilization and function. Developmental Biology 298 155-166. (doi:10.1016/j.ydbio.2006.06.024)

Quinlan AR \& Hall IM 2010 BEDTools: a flexible suite of utilities for comparing genomic features. Bioinformatics 26 841-842. (doi:10.1093/ bioinformatics/btq033)

Richter JD \& Lasko P 2011 Translational control in oocyte development. Cold Spring Harbor Perspectives in Medicine 3 a002758. (doi:10.1101/ cshperspect.a002758)

Robinson MD, McCarthy DJ \& Smyth GK 2010 edgeR: a bioconductor package for differential expression analysis of digital gene expression data. Bioinformatics 26 139-140. (doi:10.1093/bioinformatics/btp616)

Robinson MD \& Oshlack A 2010 A scaling normalization method for differential expression analysis of RNA-seq data. Genome Biology 11 R25. (doi:10.1186/gb-2010-11-3-r25)

Rodgers AB, Morgan CP, Leu NA \& Bale TL 2015 Transgenerational epigenetic programming via sperm microRNA recapitulates effects of paternal stress. PNAS 112 13699-13704. (doi:10.1073/ pnas.1508347112)

Sahakian E, Powers JJ, Chen J, Deng SL, Cheng F, Distler A, Woods DM, Rock-Klotz J, Sodre AL \& Youn J-I 2015 Histone deacetylase 11: a novel epigenetic regulator of myeloid derived suppressor cell expansion and function. Molecular Immunology 63 579-585. (doi:10.1016/j. molimm.2014.08.002)

Sato M \& Sato K 2013 Dynamic regulation of autophagy and endocytosis for cell remodeling during early development. Traffic 14 479-486. (doi:10.1111/tra.12050)

Saunders CM, Larman MG, Parrington J, Cox LJ, Royse J, Blayney LM, Swann K \& Lai FA 2002 PLC $\zeta$ : a sperm-specific trigger of Ca 2+ oscillations in eggs and embryo development. Development 129 3533-3544.

Skerget S, Rosenow MA, Petritis K \& Karr TL 2015 Sperm proteome maturation in the mouse epididymis. PLOS ONE $\mathbf{1 0}$ e0140650. (doi:10.1371/journal.pone.0140650)

Stitzel ML \& Seydoux G 2007 Regulation of the oocyte-to-zygote transition. Science 316 407-408. (doi:10.1126/science.1138236)

Stoeckius M, Grün D, Kirchner M, Ayoub S, Torti F, Piano F, Herzog M, Selbach M \& Rajewsky N 2014a Global characterization of the oocyte-to-embryo transition in Caenorhabditis elegans uncovers a novel mRNA clearance mechanism. EMBO Journal e201488769. (doi:10.15252/embj.201488769)

Stoeckius M, Grün D \& Rajewsky N 2014b Paternal RNA contributions in the Caenorhabditis elegans zygote. EMBO Journal 33 1740-1750. (doi:10.15252/embj.201488117)

Tadros W \& Lipshitz HD 2009 The maternal-to-zygotic transition: a play in two acts. Development 136 3033-3042. (doi:10.1242/dev.033183)

Tang F, Barbacioru C, Nordman E, Li B, Xu N, Bashkirov VI, Lao K \& Surani MA 2010 RNA-Seq analysis to capture the transcriptome landscape of a single cell. Nature Protocols 5 516-535. (doi:10.1038/ nprot.2009.236)

Wang G, Guo Y, Zhou T, Shi X, Yu J, Yang Y, Wu Y, Wang J, Liu M \& Chen X 2013 In-depth proteomic analysis of the human sperm reveals complex protein compositions. Journal of Proteomics 79 114-122. (doi:10.1016/j. jprot.2012.12.008)

Wang S, Kou Z, Jing Z, Zhang Y, Guo X, Dong M, Wilmut I \& Gao S 2010 Proteome of mouse oocytes at different developmental stages. PNAS 107 17639-17644. (doi:10.1073/pnas.1013185107)

Warde-Farley D, Donaldson SL, Comes O, Zuberi K, Badrawi R, Chao P, Franz M, Grouios C, Kazi F \& Lopes CT 2010 The GeneMANIA prediction server: biological network integration for gene prioritization and predicting gene function. Nucleic Acids Research 38 W214-W220. (doi:10.1093/nar/gkq537)

Watanabe Y, Khodosevich K \& Monyer H 2014 Dendrite development regulated by the schizophrenia-associated gene FEZ1 involves the ubiquitin proteasome system. Cell reports 7 552-564. (doi:10.1016/j. celrep.2014.03.022)

Xue Z, Huang K, Cai C, Cai L, Jiang C-y, Feng Y, Liu Z, Zeng Q, Cheng L \& Sun YE 2013 Genetic programs in human and mouse early embryos revealed by single-cell RNA (thinsp) sequencing. Nature 500 593-597. (doi:10.1038/nature12364)

Yuan S, Schuster A, Tang C, Yu T, Ortogero N, Bao J, Zheng H \& Yan W 2015 Sperm-borne miRNAs and endo-siRNAs are important for fertilization and preimplantation embryonic development. Development 143 635-647. (doi:10.1242/dev.131755)

Yurttas P, Morency E \& Coonrod SA 2010 Use of proteomics to identify highly abundant maternal factors that drive the egg-to-embryo transition. Reproduction 139 809-823. (doi:10.1530/REP-09-0538)

Received 21 February 2017

First decision 21 March 2017

Revised manuscript received 8 September 2017

Accepted 15 September 2017 